\title{
BEYONDCANNED TELEVISION
}

\section{BBC EARTH'S GLOBAL COMMUNITY BUILDING AND COPRODUCTION ADVENTURE IN THE CASE OF TENCENT VIDEO}

\author{
Lisa Lin \\ Royal Holloway, University of London \\ Lisa.Lin@rhul.ac.uk \\ lisalinfilms@gmail.com
}

\begin{abstract}
The October of 2018 saw the creation of BBC Earth Tribe, a global online brand representing BBC Natural History Unit (NHU)'s programming on Tencent Video, one of China's leading online streaming services. Besides providing over 650 hours of BBC documentaries to Chinese online audiences, BBC Earth Tribe delivers unprecedented access to creators from BBC NHU through interactive screen forms and offline events. This article offers a study of BBC Earth's global strategies in its partnerships with one of the largest Chinese digital platforms, Tencent, in terms of coproduction and online community building beyond traditional canned television distribution. It examines Project Penguin, which has formalised coproduction partnerships between BBC Studios and Tencent Online Media Group (OMG) since October 2018. The distribution partnerships involve not only pre-sales of BBC Earth's flagship documentaries but also coproduction and online community building on Tencent-run platforms, from streaming services to social media platforms. By examining BBC Earth's distribution strategies in the Chinese media landscape from the early 2000s, the paper aims to theorise distribution strategies between BBC Studios and Tencent Video and its socio-cultural implications on television distribution in the digital, multiplatform era of convergence.
\end{abstract}

Keywords: BBC Earth, documentary, coproduction, distribution, BBC Studios, Tencent Video, Internet television

\section{Introduction}

Media industries across the globe have been undergoing a digital shift in their organizational structures, industry strategies and programming practices. Digital technologies have disrupted the traditional logics of media production and distribution. Interactive media technologies have led to a proliferation of opportunities for media makers to reconceptualise linear programmes into online interactive content. Online streaming services, from Netflix and Amazon Prime to YouTube, have significantly transformed and disrupted the logics of production, distribution and reception of international documentaries. Television, as a business, has been heavily influenced by distribution technologies, deregulation and privatisation across different countries. ${ }^{1}$ With the fragmentation of audiences, platforms and revenues, 
broadcasters across the globe have been struggling to navigate the new media landscape, maintain online relevance and monetise their content across territories and platforms. Major media players have been adjusting their business models and rethinking the ways that media content moves through "space (flows) and time (windowing)". ${ }^{2}$

Recent decades have seen a momentous growth in international co-production and the sales of formats where international television companies are heavily involved in a range of businesses, including co-production financing, the licencing management of format production, intellectual property, licensing merchandise and branding marketing across multiple platforms and markets. ${ }^{3}$ Having acknowledged the limitation of traditional canned distribution, broadcasters and production companies have started exploring the potential of co-production partnerships and format trades. Public service broadcasters have come to rely on revenues from international sales to aid in production budgets as an integral part of their public service remit. ${ }^{4}$ Having faced the licence fee crisis, the British Broadcasting Corporation $(\mathrm{BBC})$ has been seeking new business opportunities through co-production and distribution with non-European territories. Merged with BBC Worldwide in 2018, BBC Studios, the focus of this study, was the commercial arm of the public service broadcast which monetised media content through international sales and coproduction. As Alastair Fothergill, Senior producer at the BBC Natural History Unit, argued in 2012, "I think the principal achievement of landmark wildlife series is a celebration of the natural world for a very, very large audience". ${ }^{5}$ NHU wildlife programmes have, as Morgan Richards ${ }^{6}$ states, evinced the tensions between "the BBC's public service values and the need for these series to appeal to global television markets". I would argue that these tensions could be balanced out through international sales, which generate revenues in order to supplement production budgets upon the slump of license fee.

In order to contribute to an extension of current debates on the shift beyond canned television distribution, this article explores the new models of international co-production partnerships and online community-building between BBC Studios and Tencent Video. Firstly, it will review recent scholarships on television coproduction and the impact of digital streaming services on the existing models of production and distribution. The second section elaborates on the research methods employed during the fieldwork, a combination of ethnography and industry and textual analysis. Thirdly, the study examines the coproduction partnerships between the BBC and Tencent Video in the case of Penguin Project and BBC Earth Tribe, followed by an examination of online screen forms on Tencent Video. In particular, I focus on three forms of what I define below as 'technologically-empowered screens': (1) BBC Earth's official fan page BBC Earth Tribe on Tencent Video; (2) BBC Earth's social media account on Wechat platform; and (3) on-screen Chinese bullet comments on BBC documentaries. Having adopted an integrated method that combines television and digital media studies, political economy of communication and global media studies, this paper aims to reconceptualise television distribution in the multi-platform, streaming era.

\section{Rethinking Television Coproduction between the UK and China}

With regard to international distribution, a majority of media scholars have focused on the circulation of film rather than the distribution of television content, "let alone television content that is not produced in the US". ${ }^{7}$ This article aims to fill in a broad research gap in television distribution between the UK and China with a case study of BBC Studios and Tencent Video. Television coproduction has helped western media corporations to circumvent control or to collaborate with Chinese media players, whilst preparing them to adapt to the changing values and local tastes of the new generations in China. ${ }^{8}$ International television distribution has taken place traditionally between companies (distributors) that have content to license and buyers (from broadcasters to online players) who need licensed content to satisfy their broadcast schedules and streaming services. ${ }^{9}$ 
The international television distribution models have changed in recent decades upon a range of factors, from the longstanding backdrops such as commercialisation and deregulation to digitalisation and the rise of alternative distribution platforms. Jeanette Steemers has pertinently theorised the transformation into two phases. The first transformation in distribution, according to Steemers, ${ }^{10}$ took place in the 1980 s and 1990 s, when deregulation and satellite television led to a momentous expansion in the number of television channels (a 'multi-channel era', to use Lotz's term). As she continues, moving forward to 2014, the creation of new digital channels and on-demand services has dramatically altered the television distribution market, which in turn disrupts old distribution patterns and provides access to new content from new players. ${ }^{11}$

Unlike most western counterparts, Chinese television currently has strict state censorship as well as a limited number of state-owned broadcast channels. Under the four-tier radio and television broadcasting structure at the county, city, provincial and national levels, Chinese television is characterised by a strong public service media culture with relatively low service costs, which arguably focus predominantly on "a narrowly defined 'basic cultural right' of access to broadcast media and on social equalization between urban and rural access to broadcast networks". ${ }^{12}$ To control the foreign content distributed on broadcast channels, the Chinese government has banned all foreign channels from broadcasting in mainland China, excluding five-star hotels and some regional areas in Guangdong province. With international OTT players (such as Netflix, Hulu and Amazon Prime) and western satellite channels (such as the BBC, Fox International Channel, Discovery and CNN) banned in mainland China, ${ }^{13}$ Chinese television has, instead, been dominated by the technological ascendency of its state-led 'digital champions'. ${ }^{14}$ The current decade has seen the rise of Chinese online video platforms and new business models (particularly the platform model of data-driven commercially-run digital giants such as BAT, Baidu, Alibaba and Tencent), which have not only disrupted the existing Chinese broadcast model but have also provided an alternative space for creative expression.

Upon the $40^{\text {th }}$ anniversary of China's Reform and Opening-up policy (1978-2018), many observers labelled the Chinese economic boom 'miraculous', one in which hi-tech has featured heavily (e.g. Mackerras, 2018). ${ }^{15}$ An array of state-led OTT services and online streaming platforms have disrupted and transformed the Chinese media landscape. From Baidu-run streaming service iQiyi, Alibaba's Youku/Tudou to Tencent Video, Chinese internet-distributed television has reshaped viewing experiences among Chinese viewers, especially the younger generations. During my fieldwork at the Asian Television Forum (ATF) in Singapore in December 2016, the newly-emerged Chinese digital players (such as Tencent Video, iQiyi, Youku, Sohu, Bilibili) dominated several large sections on the market floor which provided a stark contrast to the broadcast-centred floor plan a decade ago. With State support, Tencent has been allowed to diversify and expand its businesses 'without the level of scrutiny or competition you might see in western countries'. ${ }^{16}$ Tencent operates its integrated Internet services across four main sectors (media, communications, online games, utilities) and seven business operations, ${ }^{17}$ including social media and online video production. The success of Tencent Video can be attributed to the massive number of MAU Wechat users (Wechat reached 1.08 billion MAUs up to the third quarter of 2018) ${ }^{18}$ who log onto Tencent Video directly through Wechat in-app scanning with monthly subscription fees automatically paid through Wechat Wallet. Launched in April 2011, Tencent Video has become one of the first-tier subscription-based video-on-demand (SVOD) platforms in mainland China, with 457 million mobile monthly active users (MAUs) as of October $2017 .{ }^{19}$

Recent decades have seen burgeoning collaboration between Chinese and British broadcasters. The coproduction deals between the BBC and Chinese television can be traced back to 2008, when the BBC and CCTV, the Chinese national broadcaster, coproduced the natural history documentary series Wild China (BBC Two, 2008) in the run-up to the 2008 Beijing Olympics. ${ }^{20}$ The strategy behind coproduction has been glocalisation: a blending of the foreign and the local. ${ }^{21}$ According to Jo Sermon, the then BBC Worldwide director of content strategy, the production process including 57 filming trips in some of the most remote regions of China, with 20 camera men - could not have been created without a local partner organisation to negotiate the bureaucratic hoops which it had to jump through to gain 
the access to unveil China's mix of ancient and modern cultures. ${ }^{22}$ David Weiland, the Executive Vice President of BBC Studios Asia, stated in a press release for Seven Worlds, One Planet (the BBC Studios Natural History Unit's (NHU) latest landmark natural history series) at BBC Media Centre in 2019:

We are excited to extend our long standing and mutually beneficial relationships with CCTV and Tencent. By partnering with companies of this calibre we are able to bring the BBC's world class natural history to Chinese audiences and invest in the next generation of landmark natural history programmes. ${ }^{23}$

Seven Worlds, One Planet features remarkable animal behaviour from the baking plains of Africa and the frozen waters of Antarctica to Asia, the biggest of all continents. Although faced with the bureaucratic and political barriers during the coproduction process, both executives believed the partnership had proved critically and financially lucrative. ${ }^{24}$ As the BBC's Director of Content Strategy stresses, the partnerships made the filming possible and secured the location permissions from 18 separate Chinese government authorities. ${ }^{25}$

Compared to mature UK-China film coproduction treaties (e.g. BFI and BAFTA coproduction funds, tax reliefs), British and Chinese broadcasters and television producers have been facing a relatively young system of international coproduction. Collaborations between Chinese and British broadcasters saw a significant growth upon the launch of the Belt-Road-Initiative (BRI) in 2015. The BRI provides not only an infrastructure-based initiative and legislative framework but also a range of cultural policy initiatives which allow governments to issue media policies and initiatives that facilitate cooperation and coproduction among different creative industries. The official visit of Chinese President Xi Jinping to London saw the commencement of the UK-China Television Coproduction Treaty, which has since delivered an annual fund of around $£ 55$ for the UK television industry to access the Chinese market. ${ }^{26}$ Together with agreements in other creative sectors (partnerships with British Museum, British Library, Tate Britain and Durham University), the coproduction treaty has facilitated the creation of Secrets of China's Forbidden City (Channel 4, 2017), Genius of the Ancient World: Confucius (BBC Four, 2017) and Chinese New Year: The Biggest Celebration on Earth (BBC Two, 2016).

\section{Methodology}

Taken as a whole, from the early years of political-economic studies, a considerable number of television scholars have embraced macro-level political economy studies on television distribution. ${ }^{27}$ Film scholars employing a political-economic approach have explored the global media business through rights management and exploitation with their top-down examinations of media policy, corporate reports and trade publications as primary sources. ${ }^{28}$ Television scholars have taken more of a cultural studies perspective considering the cultural dimensions of distribution decisions in television industries. ${ }^{29}$ Global media studies scholars, such as Michael Curtin's 2007 study on the globalisation of Chinese film and television, have investigated how local, regional and global distribution networks are structured and how media content flows through regions and across platforms. ${ }^{30}$ Macro-level studies can by no means reveal how media institutions actually function, such as "who makes decisions, how various divisions interact, or what level of centralized coordination and control might exist" . 31 There is little media scholarship that examines the micro-level genesis behind the top-down national and institutional strategies. This article thus aims to contribute to this gap in the research in coproduction deals beyond canned television distribution.

From the 1970s, the BBC Natural History Unit (NHU) has produced some of the most powerful and iconic visions of wildlife and nature with its commercial potential being exploited across a range of formats, including international television sales, books, DVDs, merchandising and online distribution rights. ${ }^{32}$ These commercial operations were formalised with the creation of BBC Earth since 2009, a global brand representing BBC wildlife content outside 
the United Kingdom across all platforms, including DVDs, licensed consumer products, feature films, live events, websites, Twitter, Facebook and programming on international satellite channels. ${ }^{33}$ According to the BBC Press Office (2012), the mission of BBC Earth is "to inspire audiences globally with the BBC's outstanding natural history content, sharing the same values and driving credit back to the BBC". In doing so, BBC NHU programmes have established a large fan community in the Chinese market.

By adopting Caldwell's integrated industrial analysis, ${ }^{34}$ this paper traverses three levels of production studies to address how innovation strategies and new technologies foster conditions for new production cultures of creativity which have, in turn, engendered new screen forms. Drawing on trade fairs, corporate reports, trade press, and digital screen forms collected between 2017 and 2018, this paper examines BBC Earth's distribution strategies with Tencent Video in mainland China. In doing so, it aims to address the following research questions:

1. In what way have digital platform operators like Tencent Video changed old distribution patterns by providing new funding models through coproduction partnerships and online distribution for broadcasters like the BBC?

2. How has internet distribution affected the ways that BBC documentaries are distributed and consumed in the Chinese context?

3. What new screen forms have emerged as distribution methods shift with the arrival of digital technologies?

In this way, this article situates BBC Earth's global strategies within what I term the technologically-empowered screen (TES) forms on Tencent Video, which promise a connected and collective viewing experience among its online fan communities ${ }^{35}$ through its hybrid tech model. Online fan community pages are argued to become important information propagation tools for media brands. ${ }^{36}$

\section{Project Penguin: Online Community Building beyond Canned Television}

Prior to 2011, Tencent Video largely streamed free, undifferentiated content, acquired from both domestic and foreign broadcasters and film studios. This period established a number of partnerships between Tencent Video and Chinese broadcasters in both coproduction and content acquisition. With the establishment of the Chinese Copyright Alliance, Tencent Video began to acquire authorised premium content from international corporations and broadcasters, from Hollywood studios and European broadcasters to Japanese public service broadcaster NHK. From the launch of Tencent's Original Strategy in 2012, Tencent Video has shifted its production strategies from providing free and undifferentiated content (as 'publisher') to producing community-orientated personalised original content (as 'producer') to premium users, with its revenue model shifting from advertising-funded 'freemium' to subscription-supported premium. Tencent Penguin Pictures have produced a wide range of original Chinese documentaries. Having recently joined Tencent Video as Vice Chief-Editor ${ }^{37}$ and Head of Documentary Lab ${ }^{38}$ in 2018, Chen Xiaoging, a former CCTV veteran, has created more than eight Tencent original documentaries, including Once Upon a Bite (Tencent, 2018; acquired by Netflix in 2019), Flavourful Origins (Tencent/Netflix, 2019). ${ }^{39}$

Partnerships with Chinese broadcasters and digital players can facilitate the access to the local market for western-based broadcasters most of whom have acknowledged the specific political, social and cultural frameworks in the Chinese landscape. These partnerships have enabled western broadcasters to acquire location permission and manage local negotiations with China's National Administration of Radio and Television and the State Council Information Office (SCIO). Western media corporations "self-adjust and refine themselves in concert with the requirements of Chinese state ideology" in the hope of a smoother means of ingress. ${ }^{40}$ The influx of culture into China must conform to the political prescriptions of the ruling Communist Party. Chinese and international broadcasters and companies are thus obliged to consider 'politics' before 'economics'. ${ }^{41}$ SCIO's China International 
Communication Centre ( $\mathrm{CICC}$ ) was responsible for not only promoting Chinese culture globally but also supervising and issuing filming permission to international broadcasters and media companies. International documentary projects must acquire permission before filming starts (Fieldwork Note, 2016). Due to the strict political censorship by the party state, news production has been strictly controlled under the CPC leaderships which sees little creative freedom in the daily production practices. Instead of issuing legislation about media control, which would provoke "debates over the meaning of the constitutional guarantee of press freedom at the National People's Congress', the Chinese government has chosen to legitimate its media structure by administrative "regulations". ${ }^{42}$ Volatile and unpredictable media regulations, rather than clear-cut legislation, has led to a grey area in apolitical genres such as comedy, drama and documentaries. As a result, documentaries, rather than news and factual content, have been the main genre Chinese media institutions acquire from BBC Studios, with a focus on natural history and cultural documentaries. ${ }^{43}$

As Lexian Zhu, Deputy Director of Documentary Content Management Centre at Tencent Video, commented:

BBC Studios is the premium documentary content provider in the world and our partnership in co-production reflects Chinese audience's interest in top level productions. We will continue to work with BBC Studios to bring best-in-class programmes to digital viewers in China. ${ }^{44}$

The BBC's Natural History Unit (NHU) presents its "natural history film-makers as discoverers and natural history footage as discoveries", implicitly presenting itself as a producer of genuine knowledge of the natural world. ${ }^{45}$ Similar to previous coproduction deals, the coproduction partnerships have not only secured the distribution deals but also facilitated the production process with location access to the landscapes and wildlife in mainland China.

As part of 'Project Penguin' launched by Tencent Online Media Group in October 2018, the partnership between BBC Studios and Tencent involves not only pre-sales and distribution deals but also incorporates the imagination and expectations of Chinese audiences into BBC documentary production. The partnership with TCL (China's largest television maker) has expanded Tencent's entertainment and live sports content from mobile screens to smart, internet-connected TVs in living rooms through over-the-top (OTT) services, further contributing to the connected and collective viewing experience that Tencent promises its premium subscribers. ${ }^{46}$ The next section will examine the screen forms on BBC Earth Tribe, which are empowered by the technological ascendency of the indigenous digital platform.

\section{B BC Earth Tribe: Collective Viewing Experience through Technologically Empowered Screen Forms}

BBC Earth Tribe's official account was launched on Tencent Video in 2017. The case of BBC Earth Tribe demonstrates the potential of not only distributing 'canned content' but also building a fan community through what I term technologically-empowered screen (TES) forms. These TES forms represent both a technologically-deterministic production and a regulatory culture that aligns creativity with the incessant march of technology. Tencent's hybrid model has empowered its online video business with a collective viewing experience and potentially fostered conditions for greater interaction and participation among its users in the case of BBC Earth Tribe. I argue that Wechat's integration into ordinary life help produce a television experience with greater creativity and connectivity through technologically-empowered screen forms (UGC, live streaming and bullet comments). Tencent Video's interface is an attempt to integrate PGC and UGC, narrative and database logics, the publishing model and the flow model, and connectedness and connectivity, ${ }^{47}$ embodying both commercially-driven and politically-compliant characteristics. 
With the perception of BBC natural history films as reliable sources of knowledge of the natural world, Chinese online users have enjoyed BBC documentary series on Tencent Video. In addition to over 650 hours of BBC Studios' natural history and documentary programmes broadcast to Tencent VIP subscribers, BBC Earth Tribe seeks to deliver unprecedented access to the series' creators - via live streaming interviews with the award-winning producers of BBC Studios' Natural History Unit. Similar to the multi-platform programming on BBC iPlayer available to British domestic audiences, BBC Earth Tribe on Tencent Video provides not only streaming services of its flagship documentaries but also a range of para-textual interactive services that extend the programme narrative. These interactive services include mini-episodes of BBC's natural history programmes, online quizzes, interactive surveys to live streaming services directly from production locations. On the landing page for BBC Earth Tribe, seven well-known BBC documentary series are displayed (see Figure 1). Figure 2A shows an interactive quiz about the BBC documentary series The Planets (BBC/PBS, 2019), asking questions such as 'how many terrestrial planets are there in the solar system?' and 'which is the largest terrestrial planet that has so far been discovered?'. Tencent users who give the correct answers (Figure 2B) will be awarded with one BBC Documentary-made notebook (Figure 2C).

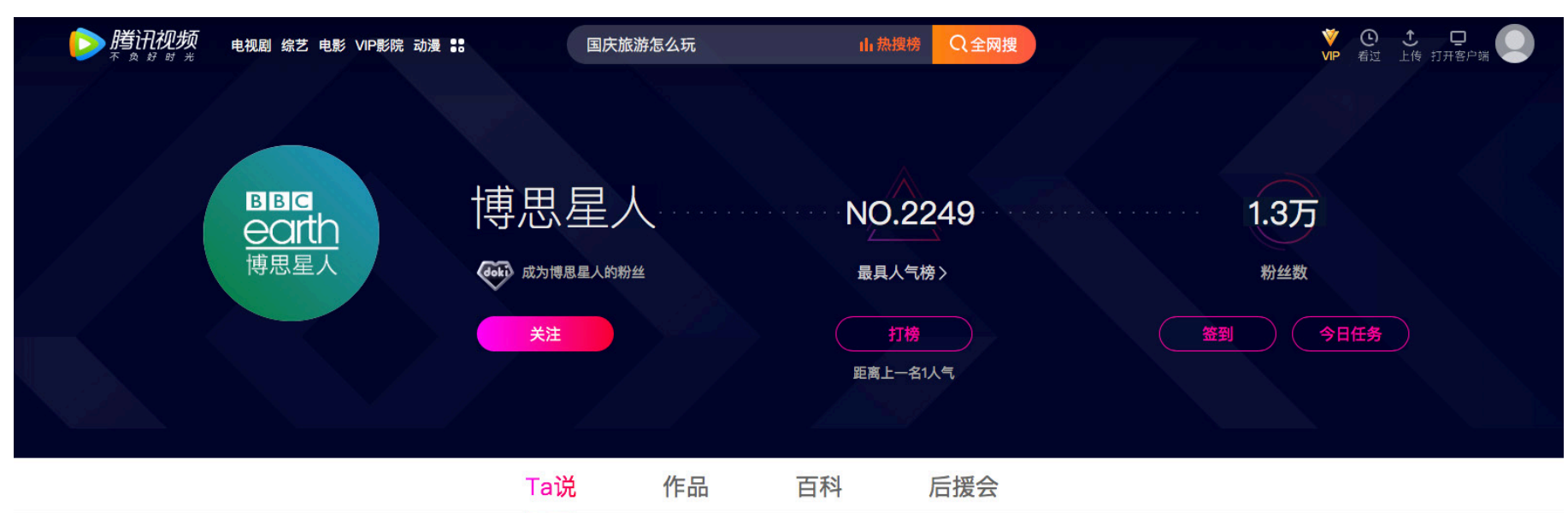

代表作品
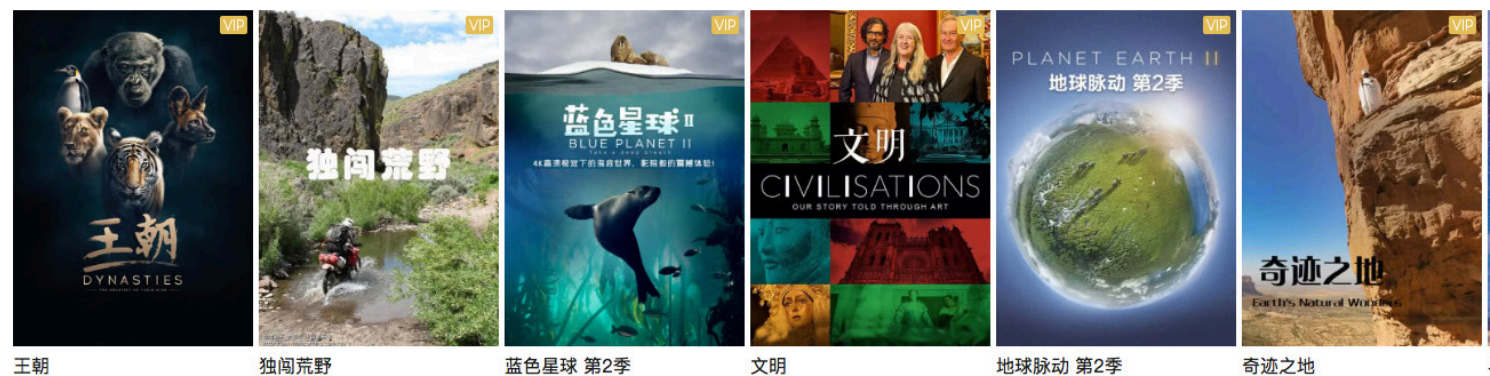

更多作品 >

Figure 1. BBC Earth Tribe's official account on Tencent Video (Screenshot as of 6th September 2019). 


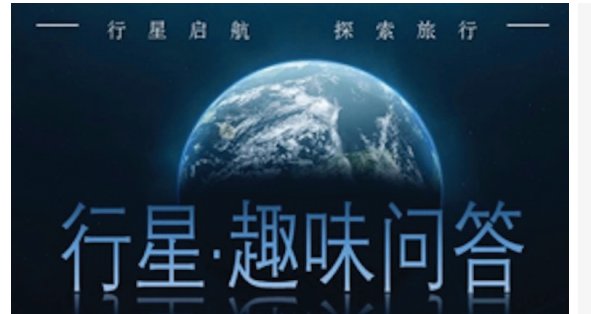

(2) 01: 太阳系有几颗类地行星?

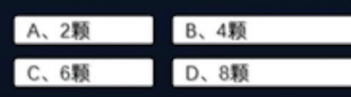

(2) 02: 下面四个选项里哪个不是 “类 地行星" ?

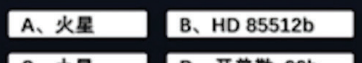

C、土星 D、开鲁勒-22b

(2) 03: 人类在太阳系外发现的第一颗类 地行星是:

A、 Corot7b B, Gliese581C C、比郎星b D、 Kepler-186t

C. B4. 宇宙已知最大的类地行星是:

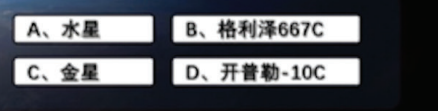

Top Comments

\section{强哥}

我看过很多BBC的纪录片, 每部都是经 典。(人类星球-家园-地球脉动1.2-冰冻 星球-王期-蓝色星球1.2-海洋-野性都市鸟瞰地球一人类我们的姑事等很多。我是 个 BBC迷

京华辅料纽扣（邓村28号）年轻.

凸2 C去一万米地底探索, 那个笔记本是博思 星人定制版呀

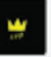

三种方式要我选择的话肯定是第一种漫步 毕竟和心爱的人漫步太空别提有多浪漫了

\section{A.}

拣尽寒枝

我都不意思问啦, 非会员可以看吗 (9)

| Author

下周三就可以看啦

ß1

梦

道

如果可以，我都要试一次
在本文下留言答案, 纪同学将从答对的同 学中选3位送出BBC专属定制管记本
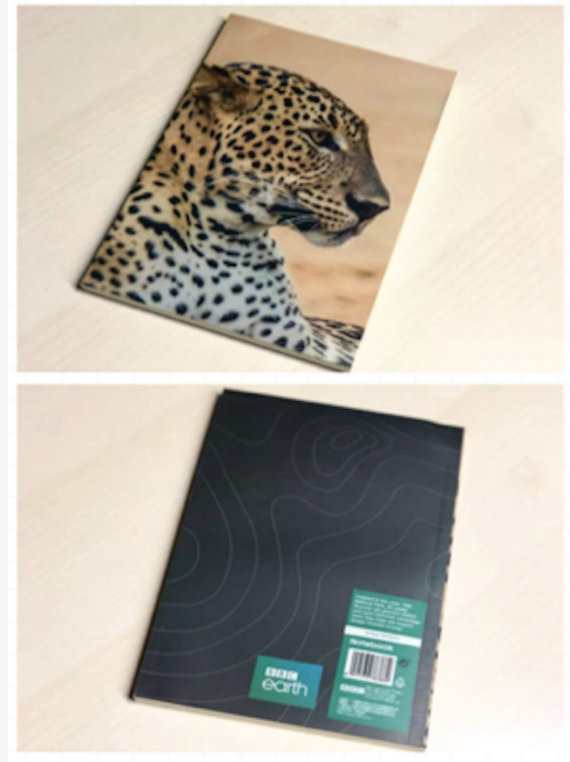

这个本儿给我一年也写不完, 很厚凸

Figure 2A. An interactive quiz on Tencent's social media platform Wechat about BBC documentary series The Planets (BBC/PBS, 2019). Figure $2 \mathrm{~B}$. Tencent users answered the questions regarding planets in BBC's Wechat official account in order to have the chance to win the BBC notebooks.

Figure 2C. Winners of the interactive quiz would get one of the BBC notebooks.

Together with its in-house social media platforms, Tencent Video has promised a collective viewing experience in our relatively alienated/atomised modern society. These screen forms include official fan page, data visualisation, bullet comments and UGC (user-generated-content) on Tencent Video. David Attenborough, the trustworthy natural history filmmaker as a branding figure in BBC's NHU has been designated an official Doki account on Tencent Video, where users can watch his works as well as fan-generated short form content on Tencent Video (Figure 3). Another form of technologically-empowered screen forms has been video feeds on BBC Earth Tribe's official Tencent page. Figures 4A-D shows a series of video feeds featuring clips from BBC flagship documentaries such as Blue Planet and Planet Earth. For instance, the first video feed in Figure 4B is mimicking an animal posture from BBC NHU series with a popular selfie pose among Chinese users: 'So happy! I found a perfect angle for selfie!'; the user of the first post in Figure 4D posts a range of selfies to urge the general public to protect wildlife which echoes the themes of most BBC NHU series. 


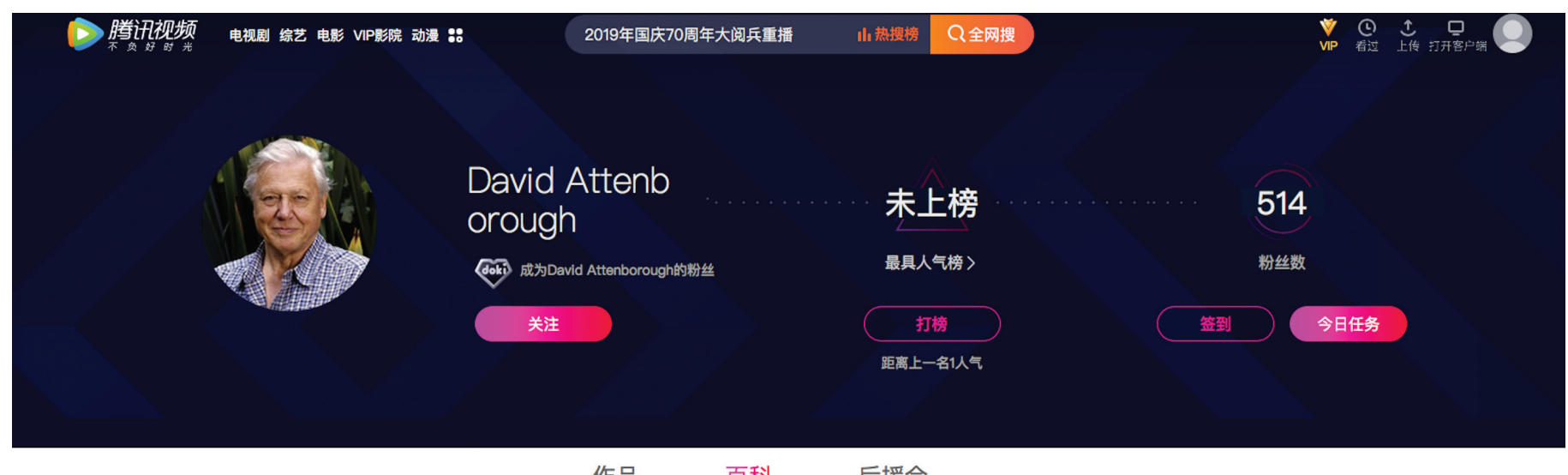

作品 百科后援会

\section{百科}

大卫·弗雷德里克·艾登保爵士 (SirDavidFrederickAttenborough, 1926年5月8日-) 于伦敦出生, 英国生物学家 英国BBC最著名的自然生态节目主持人和制作人。自1980年代忪灾人口的《生命之源》(LifeonEarth)、《生

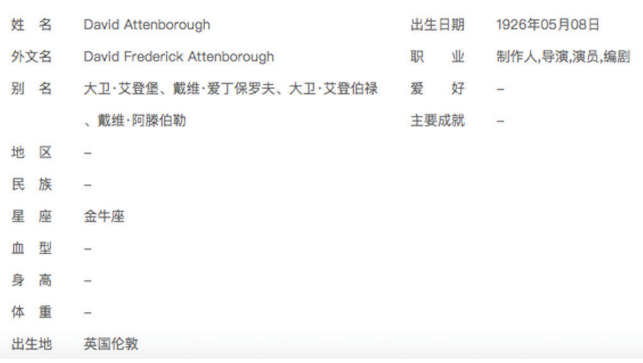

Figure 3. David Attenborough's Tencent Doki official account (Screenshot as of 6th September 2019).

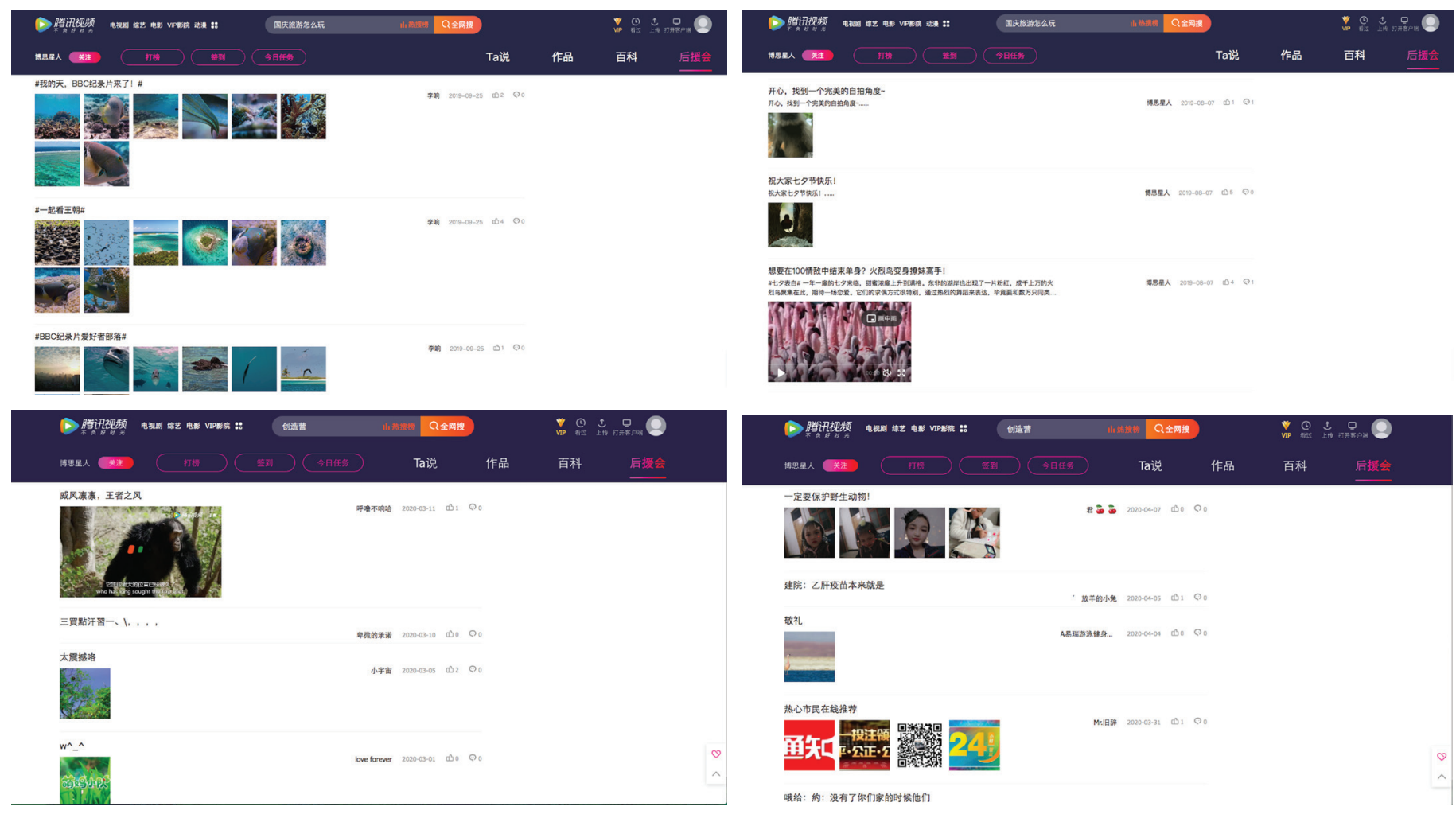

Figure 4A-D. BBC Earth Tribe's video feeds on its official Tencent Video account (Screenshot as of $7^{\text {th }}$ April 2020). 

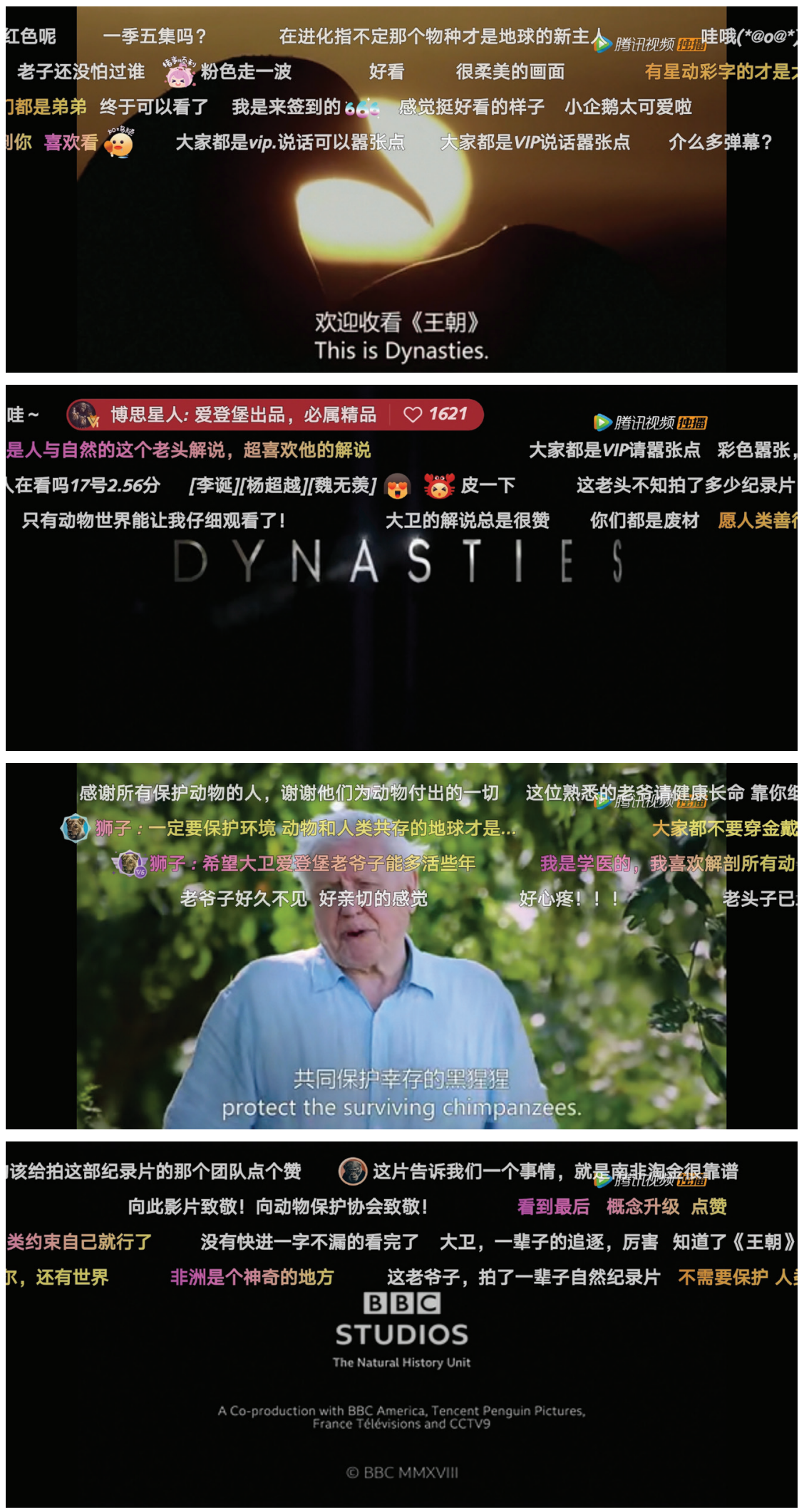

Figure 5A-D. Online streaming services of the first episode of Dynasties (BBC, 2018) on Tencent Video with real-time user-generated bullet comments on screen (Screenshots as of $10^{\text {th }}$ September 2019). 


\section{| 粉丝大数据}

$72 \%$
$28 \%$

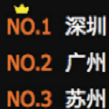

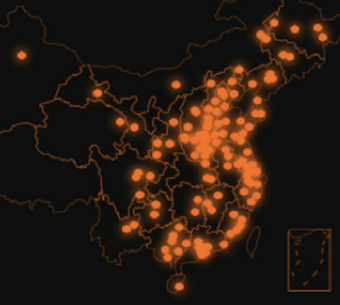
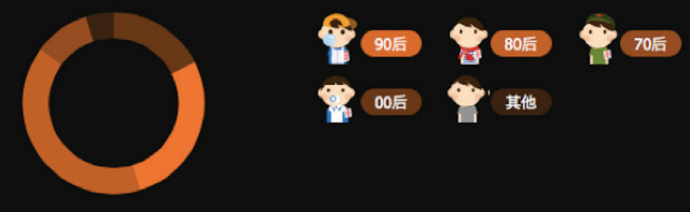

谓 00 后

Figure 6. Audience data visualisation at the bottom of the Tencent Video website (including region, age, gender, astrological sign).

Epitomising the participatory culture of the Chinese digital generation, Danmu ${ }^{48}$ enables users to see live streaming videos and other users' messages while interacting with each other simultaneously (agree, disagree, criticism or volunteering subtitle foreign content) with a high degree of real-time online interactions and grassroots participation. Danmu provides a discussion arena to debate social issues in real time, at the specific screen time of the video, engendering a collective viewing experience among Chinese online communities in the atomised society. What differs Tencent's interface from other digital streaming services lies in the integration of social media services ${ }^{49}$ in the video aggregator platform, allowing users to share the comments, viewing histories and screenshots easily with their friends on Wechat.

Online streaming service of Dynasties with real-time danmu on Tencent Video has reached 260 million clicking rates as of $23^{\text {rd }}$ April 2020. The on-screen comments enable individual online users to create a collective viewing experience through real-time interactivity, such as comments in Figure 5A-D: 'Great documentary production team', 'I like the familiar voice from Sir David Attenborough', 'We are all VIP users. Let's be bold!', 'David Attenborough is the guarantee of quality', 'David has dedicated his whole life in national history documentaries', 'I've finished watching the episode without fast-forwarding one second'.

Online users can access the visualisation of the audience matrix at the bottom of the programme's website, including users by region and by demographics such as gender, age, and even astrological sign. As such, Tencent users are able to access the data visualisation and get to know their peer viewers who are interested in watching specific documentary series. Public access to user demographics is a gateway not only for viewers to form collective viewing experiences and get to know fellow viewers, but also for potential sponsors and advertisers to access online performance of Tencent programmes (IV19, 19/12/2017, Beijing). Similar to the official fan pages and on-screen bullet comments, data-driven visualisation of viewers' matrix (see Figure 6) further enhances the collective viewing experience in the fast-paced urban cities. Danmu provides a discussion arena to debate real-time on criticism social 
issues at the specific screen time of the video, engendering a collective viewing experience among Chinese online communities in the relatively isolated, modern society. Big data not only provides detailed viewing data statistics for producers who are eager to understand daily viewing habits, but also generates new screen forms and production methods that incorporate online statistics. These TES forms maximise the potential of real-time interaction empowered through digital technologies, which not only allow audiences real-time interaction but also help media companies like BBC Studios and Tencent Video grasp users' preferences without time delays.

\section{Conclusion}

This article analysed the 'Project Penguin' launched by Tencent Online Media Group in October 2018, which has formalised industry partnerships between BBC Studios and Tencent Video in not only distribution deals but also coproduction and online community building for BBC Earth's flagship documentaries. After tracing the history of coproduction between the BBC and Chinese media institutions since the early 2000s, this article theorised what the coproduction between BBC Studios and Tencent Video may yield and what its online presence suggests about global television production and distribution in the digital, multiplatform and convergence era. It is through the coproduction process that BBC Studios manages to incorporate the cultural appetites and expectations from Chinese audiences into documentary production which has been shaped by a set of commercial, technological, local and global forces in play.

Within the ecology of SVOD streaming services, Tencent's online community building strategies have created a high degree of interactivity and participation through a range of technologically-empowered screen forms. BBC Earth Tribe's interactive services on Tencent Video have redefined television coproduction models in the streaming, multiplatform era. Transnational television channels are arguably de-territorialised in line with their multinational audiences, cross-border coverage and international production operations. ${ }^{50}$ BBC's partnership with Tencent Video can be read as a reflection of its global strategies in the post-Brexit era, exploring potential partnerships beyond the European sphere. It can be also understood as a shift in the BBC's distribution strategies from linear broadcasting to digital streaming services. Unlike analogue mass media distribution, online streaming services add a new dimension to the production, distribution and consumption of the BBC's legendary documentaries, shaped by big data, platform capitalism and grass-roots online communities.

\section{Notes}

1. Albert Moran, "Configuration of the New Television Landscape", in A Companion to Television, ed. Janet Wasko (Malden, MA: Blackwell, 2005), 291-307.

2. Alisa Perren, "Rethinking Distribution for the Future of Media Industry Studies," Cinema Journal 52, no. 3 (2013): 167.

3. Jeannette Steemers, "Selling Television: Addressing Transformations in the International Distribution of Television Content", Media Industries Journal 1, no. 1 (2014): 44-5.

4. Timothy Havens, Global Television Marketplace (London: BFI, 2006), 58.

5. Morgan Richards, "Global Nature, Global Brand: BBC Earth and David Attenborough's Landmark Wildlife Series", Media International Australia 146, no. 1 (2013): 143.

6. Ibid.

7. Steemers, "Selling television", 45.

8. Anthony Fung, Global Capital Local Culture: Localization of Transnational Media Corporations in China (New York: Peter Lang, 2008), 22. Fung's 2008 work examines the discourses from globalisation to glocalisation since the entry of international media and cultural capital to the Chinese market since the 1990s.

9. Steemers, "Selling television", 45.

10. Ibid.

11. Ibid. 
12. Yik Chan Chin, "Public service broadcasting, public interest and individual rights in China", Media, Culture \& Society 34 , no. 7 (2012): 898.

13. Although some leeway can be found in five-star hotels, international corporations and ordinary households in Guangdong province, state control still restricts audiences from accessing foreign television channels.

14. Elaine Jing Zhao., "Negotiating State and Copyright Territorialities in Overseas Expansion: The Case of China's Online Video Streaming Platforms," Media Industries 5, no. 1 (2018): 106.

15. Colin Mackerras, "40 years of reform in China: Truly remarkable change since 1978," The State Council Information Office, The People's Republic of China, December 16, 2018, http://english.scio.gov.cn/in-depth/2018-12/06/content_74246427. htm?gclid=EAlalQobChMI_pTNg5033wIVDxgbCh0U2wWNEAEYASAAEglaRfD_BwE

16. Steemers, "Selling television", 45.

17. Seven business operations include Wechat Group (WXG), Interactive Entertainment Group (IEG), Mobile Internet Group (MIG), Online Media Group (OMG), Technical Engineering Group (TEG) and Corporate Development Group (CGD).

18. "Number of monthly active WeChat users from 3rd quarter 2011 to 3rd quarter 2018 (in millions)," Statista, 2019, https://www. statista.com/statistics/255778/number-of-active-wechat-messenger-accounts/

19. Ibid.

20. Oliver Luft, "Wild China - how the BBC cut its first co-production deal with a Chinese broadcaster," The Guardian, October 22, 2008, https://www.theguardian.com/media/organgrinder/2008/oct/22/chinathemedia1

21. Joseph Straubhaar, World Television: From Global to Local (London: Sage Publications, 2007), 149.

22. Ibid.

23. "BBC Studios signs Seven Worlds, One Planet co-production deal with CCTV and Tencent Penguin Pictures in China," BBC, June 24, 2019, https://www.bbc.co.uk/mediacentre/bbcstudios/2019/bbc-studios-signs-co-production-deal-with-cctv-and-tencent

24. Ibid.

25. Ibid.

26. "Pact welcomes UK - China TV co-production treaty ahead of UK/China creative exchange programme," Pact, December 6, 2016, http://www.pact.co.uk/news-detail.html?id=pact-welcomes-uk-china-tv-co-production-treaty-ahead-of-uk-chinacreative-exchange-programme

27. Paul McDonald, Video and DVD Industries (London: BFI: 2007).

28. Alisa Perren, "Rethinking distribution for the future of media industry studies," Cinema Journal 52, no. 3 (2013): 166.

29. Ibid.

30. Ibid.

31. Amanda, D. Lotz, "Industry-Level Studies and the Contributions of Gitlin's Inside Prime Time", in Production Studies: Cultural Studies of Media Industries, eds. Vicky Mayer, Miranda J. Banks, and John T. Caldwell (London: Routledge, 2009), 25-38.

32. Richards, "Global Nature, Global Brand".

33. Ibid.

34. John T. Caldwell, Production Culture: Industrial Reflexivity and Critical Practice in Film and Television (Durham, NC: Duke University Press, 2008).

35. Chinese online communities are comprised of both millennials and generation $Z$.

36. Robert Davis and Lee Phillip McGinnis, "Conceptualizing Excessive Fan Consumption Behavior," Journal of Retailing and Consumer Services 28, (2016): 252-62.

37. See Chen Danqing's Doki Page on Tencent Video: https://v.qq.com/x/star/165321

38. "Zuopin (Production Titles)", Doc Labs, 2019, http://doclabs.com.cn/zuopin/index.html

39. See Netflix's streaming service Flavorful Origins: https://www.netflix.com/g b/title/80991060

40. Fung, Global Capital Local Culture, 29.

41. Ibid., 29, 193.

42. Yuezhi Zhao, Communication in China: Political Economy, Power, and Conflict (Lanham: Littlefield, 2008$), 26$.

43. BBC News was completely banned on Tencent Video (including BBC China's website, Tencent Video and BBC News's Chinese App). As one executive at Tencent Live Streaming explains, 'we used to have the live signal from BBC News but realised it is so dangerous! What if there is a piece of political news about Taiwan or Tibet right after some cultural news? We will be doomed' (IV12, Beijing, 22/10/2016).

44. "BBC Studios signs Seven Worlds, One Planet co-production deal with CCTV and Tencent Penguin Pictures in China," BBC, June 24, 2019, https://www.bbc.co.uk/mediacentre/bbcstudios/2019/bbc-studios-signs-co-production-deal-with-cctvand-tencent

45. Jean-Baptiste Gouyon, "The BBC Natural History Unit: Instituting Natural History Film-Making in Britain," History of Science 49, no. 4 (2011): 425-51.

46. Ibid.

47. José Van Dijck, "Datafication, Dataism and Dataveillance: Big Data between Scientific Paradigm and Ideology", Surveillance \& Society 12, no. 2 (2014): 207 
48. Originating in Japanese online platform Niconico in 2006, Danmu, displayed as scrolling marquee comments synchronised to a specific playback time, has been widely adopted by Chinese video platforms from first-tier players iQiyi and Tencent Video to UGC platforms like Bilibili and Kwai. See Ming He, Yong Ge, Enhong Chen, Qi Liu, and Xuesong Wang, "Exploring the Emerging Type of Commentfor Online Videos: DanMu," ACM Transactions on the Web 12, no. 1 (2017): 2.

49. Users are required to log in Tencent Video through either Wechat or $Q Q$ accounts, two Tencent-owned social media platforms which have dominated the social media landscape in mainland China with western counterparts (Facebook, Twitter, etc) being banned.

50. Jean K. Chalaby, "Television for a New Global Order: Transnational Television Networks and the Formulation of Global Systems," Gazette 65, no. 6 (2003): 457-72.

\section{B i o graphy}

Lisa Lin is an Assistant Producer of StoryFutures at Royal Holloway, University of London. Before joining Royal Holloway, she worked as a Lecturer in Media Studies at the School of Arts, University of Kent where she led Podcasting Production and Media Audiences as part of BA Media Studies programme. Lisa holds a PhD in Media and Communications, an MA in International Broadcasting at Royal Holloway, University of London and a Diploma in Factual Television Production at the National Film and Television School. She has worked as a television producer in the UK, China and Singapore with expertise in factual and documentary production, including producing works for National Geographic, Channel 4 and Channel News Asia. Having been an ethnographer of television and digital media production, her research interests revolve around the correlations between technology and creativity and how digital technologies have transformed and disrupted the traditional logics of media production and distribution between the Western and Eastern contexts on macro-, meso-, and micro-levels. Her goal across these research projects is to politicize the digital transformation of media industries and practices at the margins of the digital and analogue. Lisa is developing research projects on the impact of big data and algorithm on viewing experiences and data surveillance in the post-network era. Lisa is the Principal Investigator for a GCRF-funded project 'How to Employ Environmental Documentaries as Visual Evidence to Engage a Wider Debate on Social Injustice Behind Air Pollution in Jingjinji (China) and Delhi (India)' in partnership with Sussex University and Beijing Normal University. She is currently in the process of publishing her ethnographic study on Chinese convergence-era television as a monograph that examines the shifting production cultures and convergence strategies in post-TVIII China. 